\title{
PENERAPAN PEMBELAJARAN SENTRA DALAM PENGEMBANGAN KECERDASAN LOGIKA MATEMATIKA ANAK USIA DINI DI TK ISLAMIC CENTER SAMARINDA
}

\author{
IMPLEMENTATION OF BEYOND CENTERS AND CIRCLE TIME IN DEVELOPMENT OF \\ MATHEMATICS LOGICS INTELLIGENCE
}

\author{
Budi Rahardjo, Titi Dwi Jayanti, Malpaleni Satriana \\ Universitas Mulawarman \\ budirahardjopaud@gmail.com
}

\begin{abstract}
Abstrak
Penelitian ini bertujuan untuk mengkaji lebih mendalam suatu data primer dan sekunder tertentu yaitu: Penerapan Model Pembelajaran Sentra Dalam Pengembangan Kecerdasan Logika Matematika Anak Usia 5-6 tahun di TK Islamic Center Samarinda. Pengumpulan data di lakukan dengan metode observasi, wawancara dan dokumentasi. Hasil penelitian menunjukkan bahwa pendekatan perencanaan yang dilakukan guru dalam penerapan model pembelajaran sentra dalam pengembangan kecerdasan Logika Matematika anak usia 5-6 tahun di TK Islamic Center Samarinda dilakukan dalam pembuatan RPPM dan RPPH, dengan pelaksanaan yang meliputi 4 pijakan yaitu pijakan lingkungan main, pijakan sebelum main, pijakan selama main, dan pijakan sesudah main semua sentra mengenalkan bentuk geometri pada kecerdasan logika matematika yang di kembangkan bisa teridentifikasi dari jenis main yang di tawarkan oleh pendidik. Hasil yang dicapai anak usia dini dari model pembelajaran sentra dalam pengembangan kecerdasan Logika Matematika pada anak usia 5-6 tahun di TK Islamic Center Samarinda yaitu Berkembang Sesuai Harapan.
\end{abstract}

Kata kunci : Pembelajaran Sentra, Kecerdasan Logika Matematika, Hasil Pembelajaran

\begin{abstract}
This study aims to examine in depth a particular primary and secondary data, namely: Implementation of the Beyond Centers and Circle Time in the Development of Mathematical Logic Intelligence in Children Aged 5-6 years at the Islamic Center Kindergarten in Samarinda. Data collection is done by the method of observation, interviews and documentation. The results showed that the planning approach taken by teachers in the Implementation of the Beyond Centers and Circle Time in the Development of Mathematical Logic Intelligence in Children Aged 5-6 years at the Islamic Center Kindergarten in Samarinda was carried out in the making of weekly learning implementation plan and daily learning implementation plan, with implementation that included 4 steps, namely the scaffolding of the playing environment, the scaffolding before play, scaffolding during play, and scaffolding after playing all centers introduce geometric shapes in the intelligence of mathematical logic that are developed can be identified from the type of play offered by educators. The results achieved early childhood from the center learning model in the development of Mathematical Logic Intelligence in children aged 5-6 years in Samarinda Islamic Center Kindergarten is Developing as Expected.
\end{abstract}

Keywords: Beyond Centers and Circle Time, Mathematical Logic Intelligence, Learning Outcomes 


\section{PENDAHULUAN}

Komitmen Gubernur Kaltim Awang Faroek Ishak dan Wakil gubernur kaltim Mukmin Faisyal untuk mewujudkan sumber daya manusia berkualitas di masa akan datang terus dilaksanakan dan jangan pernah diragukan. Bahkan peningkatan kualitas tersebut dibangun sejak pendidikan anak usia dini (PAUD), karena pendidikan anak usia dini sangat menentukan bagaimana perkembangan produktivitas manusia di masa akan datang.

Pada Pasal 28 Undang - Undang Sistem Pendidikan Nasional No. 20/2003 ayat 1, disebutkan bahwa anak usia dini adalah anak yang masuk dalam rentang usia 0-6 tahun yang berada dalam proses pertumbuhan dan perkembangan yang bersifat unik. Yaitu, pola pertumbuhan dan perkembangan (koordinasi motorik halus dan kasar), inteligensi (daya pikir, daya cipta, kecerdasan emosi dan kecerdasan spritual), sosial emosional, bahasa dan konumikasi yang khusus sesuai dengan pertumbuhan dan perkembangan anak.

Howard Gardner mengemukakan delapan (8) aspek kecerdasan jamak yang perlu dikembangkan, yaitu: kecerdasan verbal-linguistik, kecerdasan logika-matematika, kecerdasan fisik/kinestetik, kecerdasan spasial, kecerdasan musikal, kecerdasan intrapersonal, kecerdasan interpersonal, dan kecerdasan naturalis. Dari delapan kecerdasan tersebut, yang diangkat pada penelitian kali ini ialah kecerdasan logika matematika yang merupakan kemampuan mengeksplorasi pola-pola, kategori, dan hubungan dengan memanipulasi objek atau simbol untuk melakukan percobaan dengan cara yang terkontrol dan teratur (Suyadi, 2014:86).

Banyak lembaga yang bergerak di bidang anak usia dini, akan tetapi belum banyak lembaga yang menggunakan multiple intelligences sebagai dasar pembelajarannya. Salah satu lembaga Pendidikan Anak usia dini yang menggunakan multiple intelligences salah satunya kecerdasan logika matematika sebagai dasar pembelajarannya adalah TK Islamic Center Samarinda yang dilaksanakan melalui pendekatan sentra sesuai dengan minat anak.

Penelitian yang dilakukan Ismatul khasanah tentang pembelajaran logika matematika anak usia dini (4-5 tahun) di TK Ikal Bulog Jakarta Timur menunjukkan, bentuk kecerdasan logika matematika yang dilaksanakan di TK IKAL I Bulog berupa konsep dasar logika matematika sederhana bentuk pengenalan seperti; (1) pengenalan angka, (2) pengenalan perbedaan, (3) Pengenalan lambang bilangan, (4) klasifikasi, (5) pengenalan bentuk geometri, 
dan (6) pengenalan warna. Bertitik tolak dari analisis hasil penelitian maka dirumuskan teori substantif sebagai berikut: "Apabila telah terlihat anak melaksanakan bentuk logika matematika seperti pengenalan angka, pengenalan perbedaan, pengenalan lambang bilangan, klasifikasi, pengenalan bentuk geometri, dan pengenalan warna, maka guru telah mengajarkan pembelajaran logika matematika".

Belum ada penelitian yang meneliti tentang pembelajaran sentra dalam pengembangan kecerdasan logika matematika khususnya pada pemahaman bentuk geometri pada anak usia 5-6 tahun. Demikian peneliti tertarik untuk mengangkat masalah ini menjadi sebuah tema penelitian yang berjudul Penerapan Model Pembelajaran Sentra Dalam Pengembangan Kecerdasan Logika Matematika Anak Usia 5-6 Tahun Di TK Islamic Center Samarinda, bagaimana pendekatan pembelajaran sentra, pelaksanaan dan bagaimana hasil yang dicapai dari proses tersebut. Dengan penelitian ini, penulis ingin mengetahui dan mengkaji berdasarkan analisis mendalam tentang bagaimana penerapan model pembelajaran sentra dalam pengembangan kecerdasan logika matematika dilapangan.

\section{METODE PENELITIAN}

\section{Jenis Penelitian}

Pendekatan yang digunakan dalam penelitian ini adalah pendekatan kualitatif. Pendekatan kualitatif adalah sebuah pendekatan penelitian yang diselenggarakan dalam setting alamiah, memerankan peneliti sebagai instrumen pengumpul data, menggunakan analisis induktif, dan berfokus pada makna menurut perspektif partisipan (Nana, 2005:94)

Sedangkan jenis penelitian ini adalah penelitian 'studi kasus' yang dipilih karena penelitian ini bertujuan mengkaji secara intensif dan mendalam suatu subjek atau objek tertentu. Studi kasus adalah penelitian yang dilakukan oleh peneliti secara kasusistik yaitu penelitian yang hanya mencurahkan perhatian terhadap kasus yang spesifik saja (Johni, 2013:63).

\section{Waktu dan Tempat Penelitian}

1. Waktu

Waktu pelaksanaan penelitian ini adalah mulai semester genap (II) tahun 2017.

2. Tempat

Penelitian ini dilaksanakan di TK Islamic Center Samarinda. Pemilihan TK Islamic Center Samarinda tidak dimaksudkan untuk mewakili kondisi-kondisi TK lainnya, akan tetapi mempelajari situasi sosial yang ada di suatu lembaga TK tersebut. 


\section{Target/Subjek Penelitian}

1. Target

Target penelitian adalah mengembangkan kecerdasan logika matematika melalui penerapan pembelajaran sentra.

2. Subjek

Subjek pada penelitian ini yaitu anak usia 5-6 tahun (kelompok B) di TK Islamic Center Samarinda.

\section{Prosedur}

Pengumpulan data di lakukan dengan metode observasi, wawancara dan dokumentasi menggunakan pedoman observasi, pedoman wawancara dan pedoman dokumentasi.

\section{Data, Intrumen, dan Teknik Pengumpulan Data}

Data yang digunakan dalam penelitian ini adalah data primer dan data sekunder. Data primer dalam penelitian ini adalah data langsung yang diperoleh dari kepala sekolah, para guru, dan peserta didik TK Islamic Center Samarinda.

Sedangkan, data sekunder dalam penelitian ini adalah data yang berhubungan dengan objek formal serta pengkayaan dalam rangka penyusunan laporan penelitian berupa dokumentasi yang diperlukan untuk menggambarkan keadaan umum TK Islamic Center, seperti visi-misi sekolah, profil anak didik dan pendidik, silabus (kurikulum) dan sebagainya.

Teknik pengumpulan data yang dilakukan meliputi: (1) metode pengamatan berperan serta (observasi partisipatif), sebagai metode utama untuk mengumpulkan data mengenai kecerdasan logika-matematika anak usia 5-6 tahun TK Islamic Center Samarinda yang bersangkutan, (2) metode wawancara mendalam yang dilakukan terhadap Kepala TK Islamic Center, guru-guru TK, dan anak didik, dan (3) metode dokumentasi, sebagai metode penunjang untuk memperoleh data/fakta di lapangan.

\section{Teknik Analisis Data}

Teknik analisis data yang digunakan melalui beberapa tahapan. Pertama, data yang telah diperoleh dari berbagai sumber, baik dari pengamatan, catatan lapangan, dan wawancara diklasifikasi sesuai dengan karakteristik masing-masing. Data dari hasil perekaman ditranskripsikan dan dikelompokkan. Kedua, data yang telah ditranskripsikan dan dikelompokkan kemudian dianalisis menggunakan tahapan analisis model alir, yang terdiri:

a. Reduksi data 
Peneliti memilih data kecerdasan logika-matematika dan data catatan lapangan dari kegiatan pembelajaran di kelas maupun di lingkungan sekolah, data kecerdasan logika-matematika yang mempunyai ciri khusus diperhatikan untuk dijadikan sebagai model kecerdasan logika-matematika. Dengan reduksi, maka peneliti merangkum, mengambil data yang pokok dan penting.

b. Penyajian data

Tahap penyajian data dilakukan dalam bentuk uraian singkat, bagan, hubungan antar kategori, dan sejenisnya. Miles dan huberman mengatakan yang paling sering digunakan untuk menyajikan data dalam penelitian kualitatif adalah dengan teks yang bersifat naratif.

c. Penarikan simpulan dan verifikasi

Peneliti menganalisis kecerdasan logika-matematika untuk membuat generalisasi awal terhadap data yang memiliki keteraturan. Setelah itu, peneliti mencari data tambahan untuk menguji generalisasi dengan ketentuan 1. Jika menentang, generalisasi awal perlu direvisi dan 2. Jika mendukung perlu diangkat menjadi teori substantif dan teori formal yang nantinya dipaparkan pada simpulan akhir.

\section{HASIL PENELITIAN DAN PEMBAHASAN}

Berdasarkan masalah yang telah dirumuskan dengan memperhatikan beberapa pertanyaan penelitian yang kemudian menghasilkan hasil penelitian serta pembahasannya sebagai berikut:

1. Perencanaan Pendekatan dalam Model Pembelajaran Sentra Dalam Pengembangan Kecerdasan Logika Matematika Anak Usia 5-6 Tahun di TK Islamic Center Samarinda

Berdasarkan dari hasil penelitian di lapangan pendekatan sentra berbasis multiple intelligences khususnya kecerdasan logika matematika di Taman Kanak-kanak TK Islamic Center meliputi RPPH dan RPPM yang dibuat sesuai dengan pengembangan kurikulum oleh TK Islamic Center yang mengacu pada Permen No. 137 mengenai Standar Penyelenggaran Pendidikan Anak Usia Dini (PAUD). Di dalam RPPH yang dibuat pendidik tidak tertulis kecerdasan logika matematika tetapi, kecerdasan jamak terkait logika matematika yang dikembangkan bisa teridentifikasi di jenis permainan yang tertulis di RPPH. Jenis permainan yang tertulis di RPPH menunjukkan bahwa terdapat pengembangan kecerdasan jamak terkait logika matematika meskipun tidak semua kecerdasan dikembangkan. 
Berdasarkan hasil penelitian atau hasil temuan menunjukkan, dalam kegiatan pembelajaran di TK Islamic terdapat 2 pendidik yaitu Guru sentra dan guru kelas Al-Islam. Rencana perencanaan Pembelajaran Harian yang dibuat oleh guru sentra berisikan komponen-komponen seperti: hari dan tanggal; kelompok usia; pertemuan; aspek pengembangan; indikator; tema; subtema; kegiatan pendukung; bahan dan alat; pelaksanaan kegiatan dan teknik penilaian yang sesuai SOP dari KTSP kurikulum TK Islamic Center. RPPM dan RPPH dibuat oleh koordinator dan guru sentra satu minggu sebelum pembelajaran dimulai kemudian disetorkan kepada Kepala Sekolah. Rencana Pelaksanaan Pembelajaran Harian (RKH) berisikan materi dan kegiatan yang akan dilakukan dalam satu hari.

2. Pelaksanaan Pendekatan dalam Model Pembelajaran Sentra Dalam Pengembangan Kecerdasan logika matematika pada pemahama bentuk geometri Anak Usia 5-6 Tahun di TK Islamic Center Samarinda

Pelaksanaan pembelajaran menggunakan pendekatan sentra berbasis multiple intelligences khususnya pada kecerdasan logika matematika pada pemahaman bentuk geometri di TK Islamic Center dibagi menjadi 6 sentra yaitu sentra seni. Sentra mengelolah tubuh, persiapan, balok, bahan alam dan main peran. Pelaksanaan pendekatan sentra berbasis multiple intelligences salah satunya kecerdasan logika matematika pada pemahaman bentuk geometri di Taman Kanak-kanak Islamic Center bisa dikatakan sudah baik.

Berdasarkan hasil penelitian Penerapan model pembelajaran sentra dalam pengembangan kecerdasan logika matematika anak dilakukan sesuai dengan tahapan usia anak. Materi yang diberikan di setiap harinya sesuai dengan acuan yang digunakan yaitu Permen Nomor 137 tentang Standar Penyelenggaran PAUD. Pelaksanaan pendekatan sentra berbasis multiple intelligences di TK Islamic Center. dilaksanakan sesuai dengan tema yang telah dibuat didalam RPPH dan RPPM. Begitu pula dengan alat dan bahan main yang juga disiapkan sesuai dengan tema yang telah dipersiapkan di setiap sentra yang telah dijadwalkan. Alat dan bahan main yang dipersiapkan disesuaikan dengan capaian perkembangan yang telah tertulis di RPPH.

Berdasarkan hasil penelitian di kelas Abdullah Marisie usia 5-6 tahun di TK Islamic Center bahwa pelaksanaan pendekatan sentra berbasis multiple intelligences terkait kecerdasan logika matematika sesuai dengan sentra yang sudah dijadwalkan yang mengacu 
pada 4 pijakan, meliputi: (1) Pijakan lingkungan main, (2) Pijakan pengalaman sebelum main, (3) Pijakan pengalaman saat main, (4) Pijakan pengalaman setelah main.

Pelaksanaan kegiaatan main pada setiap sentra mengaitkan kecerdasan logika matematika pada semua panca indra anak dalam pemahaman bentuk geometri. Sebagaimana yang telah dikemukakan oleh Montolalu, Bermain bermanfaat mengasah panca indra dan melakukan penemuan karena Ketajaman penglihatan dan pendengaran sangat penting dan sangat di butuhkan anak usia TK sehingga perlu segera di kembangka karena akan membantu anak lebih mudah belajar mengenal dan mengingat bentuk simbol-simbol tulisan yang akan membantu anak belajar membaca dan menulis di SD.

Berdasarkan hasil penelitian, kegiatan main di TK Islamic center khususnya pada usia Taman Kanak-kanak yang mengembangkan kecerdasan logika matematika pada pemahaman bentuk geometri di setiap sentra sebagai berikut:

a.Guru Membantu anak agar lebih peka dalam mempelajari tentang perbedaan dan persaman bentuk (selanjutnya termasuk ke dalam klasifikasi) di lingkungannya dan bertujuan dapat membedakan satu dengan yang lainnya.

b.Anak dapat belajar dari beberapa bentuk dasar geometri itu di mana mereka dapat menunjukkan berdasarkan apa yang ada di lingkungannya (Misalnya: saya meletakkan buku di atas meja yang berbentuk segi empat).

c.Pengenalan bentuk geometri dilakukan pada setiap kegiatan sentra dengan cara 1. finger painting bentuk lingkaran 2. Membuat bangunan dengan balok 3. Membuat rumah dari segitiga (Hijau) dan segiempat(merah) 4. Melompat pada pola lingkaran, segitiga, persegi dan persegi panjang 5. Menyanyikan lagu topi saya bundar dengan gerakan 6. Membuat lingkaran besar, lingkaran kecil dan setengah lingkaran.

3. Hasil yang dicapai AUD dari model pembelajaran sentra dalam pengembangan kecerdasan logika matematika pada anak usia 5-6 tahun di TK Islamic Center Samarinda.

Penilaian pembelajaran dengan menggunakan pendekatan sentra berbasis multiple intelligences di TK Islamic Center, menggunakan beberapa teknik yaitu observasi, anekdot, ceklis, dan pemberian tugas. Semua hasil pembelajaran dari beberapa teknik tersebut diakumulasikan menjadi satu laporan yaitu laporan akhir semester dan laporan tengah semester yang diberikan kepada orang tua peserta didik. Laporan tengah semester dan 
laporan akhir semester ditulis berdasarkan aspek nilai agama dan moral, sosial emosional, bahasa, kognitif, dan fisik motorik.

Penilaian menggunakan teknik ceklis dilakukan menggunakan kategori dengan beberapa indikator pencapaian anak dalam pembelajaran. Ceklis dilakukan menggunakan kode yang dibuat TK Islamic Center Samarinda untuk memudahkan pendidik dalam melakukan penilaian. Kode tersebut merupakan aspek-aspek perkembangan anak meliputi; NAM (Nilai Agama dan Moral), SOSEM (Sosial Emosional), B (Bahasa), K (Kognitif), FM (Fisik Motorik), dan S (Seni).

Laporan tengah semester di TK Islamic Center disusun berupa ceklis yang menggunakan kategori tertentu. Pembuatan kategori tersebut untuk memudahkan orang tua dalam membaca dan memahami perkembangan yang terjadi pada peserta didik. Kategori tersebut meliputi :

\begin{tabular}{cl}
\hline Kategori & \multicolumn{1}{c}{ Keterangan } \\
BB & Anak Belum Berkembang, masih banyak dibantu guru \\
MB & Anak Mulai Berkembang dengan sedikit di bantu guru \\
BSH & Anak Berkembang Sesuai Harapan, hasil belum maksimal \\
BSB & $\begin{array}{l}\text { Anak Berkembang Sangat Baik tanpa bantuan guru dan } \\
\text { hasil sangat maksimal }\end{array}$ \\
\hline
\end{tabular}

Tabel 1 Kategori Penilaian TK Islamic Center Samarinda

Penilaian pembelajaran dengan menggunakan pendekatan sentra berbasis multiple intelligences di TK Islamic Center Samarinda mencakup beberapa kecerdasan jamak pada anak meskipun belum semua kecerdasan dikembangkan. Kecerdasan yang sudah dikembangkan di TK Islamic Center Salah satunya kecerdasan logika matematika. Hal ini bisa dilihat dalam materi-materi yang dan kegiatan yang diberikan pada setiap aspek perkembangannya.

\section{SIMPULAN DAN SARAN}

\section{Simpulan}

Perencanaan yaitu pendidik membuat Rencana Pelaksanaan Pembelajaran Harian dan Rencana Pelaksanaan Pembelajaran Mingguan satu minggu sebelum kegiatan pembelajaran berlangsung. RPPH dan RPPM tersebut disetorkan terlebih dahulu kepada Kepala Sekolah untuk diteliti dan disetujui. RPPH yang dibuat pendidik berisi komponen yang menggambarkan 
pembelajaran setiap harinya, akan tetapi tidak tertulis macam-macam kecerdasan logika matematika yang dikembangkan.

Dalam pelaksanaan pembelajaran pendekatan sentra berbasis multiple intelligences salah satunya kecerdasan logika matematika pada anak usia 5-6 tahun di TK Islamic center, bisa teridentifikasi macam kecerdasan jamak yang dikembangkan. Macam kecerdasan jamak yang sudah dikembangkan meliputi kecerdasan musik, bahasa, gerakan badan, visual spasial, logikamatematika, antar-pribadi, spiritual dan naturalis. Kecerdasan jamak yang dikembangkan bisa teridentifikasi dari jenis main yang ditawarkan oleh pendidik.

Hasil yang di capai anak usia 5-6 tahun di TK Islamic Center pada level 11 yaitu tahap pemahaman bentuk dasar geometri, yang dilakukan dengan beberapa teknik yaitu observasi, ceklis, pemberian tugas dan anekdot. Dari semua hasil penilaian dengan teknik tersebut dikumpulkan menjadi sebuah portofolio. Hasil belajar anak tentang bentuk dasar geometri yaitu berkembang sesuai harapan dan selama mengikuti pembelajaran dilaporkan oleh pendidik kepada orang tua berupa laporan tengah semester dan laporan akhir semester.

\section{Saran}

Penelitian ini masih sangat jauh dari kata sempurna serta apa yang dihasilkan oleh peneliti bukanlah hasil akhir, sehingga perlu diadakan penelitian lebih lanjut khususnya pada pembelajaran sentra pada pengembangan kecerdasan jamak salah satunya kecerdasan logika matematika anak Usia 5-6 Tahun Di TK Islamic Center Samarinda.

\section{DAFTAR PUSTAKA}

Dimyati, Johni. 2013. Metodologi Penelitian Pendidikan \& Aplikasinya Pada Pendidikan Anak Usia Dini (PAUD). (Jakarta: Kencana Prenada Media Gruop).

Khasanah, Ismatul. 2013. Pembelajaran logika matematika anak usia dini (4-5 tahun) di TK Ikal Bulog Jakarta Timur. Jurnal Penelitian PAUDIA.

Montolalu, dkk. 2005. Bermain dan Permainan anak. Jakarta: Universitas Terbuka.

Musfiroh, Tadkiroatun. 2008. Pengembangan Kecerdasan Majemuk. Jakarta: Universitas Terbuka.

Muliawan, Jasa Ungguh. 2014. Metodelogi Penelitian Pendidikan Dengan Studi Kasus. Yogyakarta: Gava Media.

Rahardjo, Budi. 2009. Kecerdasan Interpersonal Anak Usia Dini (Kajian Kualitatif dan Keluarga di TK At-Taqwa Rawamayun.) Disertasi Pascasarjana. Jakarta: IKIP UNJ. 
Rosidah, Laily. 2014. Peningkatan Kecerdasan Visual Spasial Anak Usia Dini Melalui Permainan Maze. Jurnal Pendidikan Anak Usia Dini. No. 2. Banten: Universitas Ageng Tirtayasa Banten.

Sukmadinata, Nana Syaodih. 2005. Metode penelitian Pendidikan. Bandung: PT. Remaja Rosdakarya.

Undang-Undang RI Nomor 20 Tahun 2003 Tentang Sistem Pendidikan Nasional (2003). Jakarta: Depdiknas. 